Instituto Internacional de Investigación y Desarrollo Tecnológico Educativo INDTEC, C.A.

DOI: https://doi.org/10.29394/Scientific.issn.2542-2987.2020.5.18.11.213-233

OAI-PMH: http://www.indteca.com/ojs/index.php/Revista Scientific/oai

Artículo Original / Original Article

\title{
¿Lo divertido se recuerda?: Humor como recurso para reducir la evasión publicitaria en redes sociales
}

Autoras: Melany Cristina Mosquera Álvarez Universidad Internacional del Ecuador, UIDE melacris98@hotmail.com Quito, Ecuador https://orcid.org/0000-0003-0877-4935

Patricia Elizabeth Hidalgo Albuja Universidad Internacional del Ecuador, UIDE phidalgo@uide.edu.ec Quito, Ecuador https://orcid.org/0000-0002-0735-8991

\section{Resumen}

En la actualidad centenares de marcas han migrado su comunicación publicitaria a las redes sociales en busca de captar la atención de una nueva generación de consumidores, los Centennials. No obstante, la percepción negativa sobre la publicidad en general y la sobresaturación de información imponen un gran reto: encontrar recursos que permitan no solo captar la atención de una audiencia sino ganar un espacio en su memoria. Por ello el propósito de la presente investigación es analizar la influencia del tono humorístico en la recordación de mensajes publicitarios exhibidos en las redes sociales. Se realizó un experimento en un universo de 30 jóvenes que pertenecen a la Generación Centennials. Los resultados revelan que el tono humorístico aumenta la probabilidad de recordación de un anuncio en consecuencia de una mayor atención, reafirmando así la eficacia del humor como recurso publicitario. sociales.

Palabras clave: humor; evasión publicitaria; centennials; redes

Cómo citar este artículo:

González, M. (2020). Diagnóstico de factores de riesgo de niños en albergue: Una propuesta estratégica para su desarrollo integral. Revista Scientific, 5(18), 193-212, e-ISSN: 2542-2987. Recuperado de: https://doi.org/10.29394/Scientific.issn.2542-2987.2020.5.18.10.193-212

Fecha de Recepción: 05-06-2020
Fecha de Aceptación: 27-09-2020
Fecha de Publicación: 05-11-2020 
Instituto Internacional de Investigación y Desarrollo Tecnológico Educativo INDTEC, C.A.

DOI: https://doi.org/10.29394/Scientific.issn.2542-2987.2020.5.18.11.213-233

OAI-PMH: http://www.indteca.com/ojs/index.php/Revista_Scientific/oai

Artículo Original / Original Article

\title{
Do you remember what is funny?: Humor as a resource to reduce advertising evasion on social networks
}

\begin{abstract}
Today, hundreds of brands have migrated their advertising communication to social networks in order to capture the attention of a new generation of consumers, the Centennials. However, the negative perception of advertising in general and the oversaturation of information pose a great challenge: finding resources that allow not only to capture the attention of an audience but also to gain space in their memory. Therefore, the purpose of this research is to analyze the influence of humorous tone in the recall of advertising messages displayed on social networks. An experiment was carried out in a universe of 30 young people who belong to the Centennials Generation. The results reveal that the humorous tone increases the probability of recalling an advertisement as a result of increased attention, thus reaffirming the effectiveness of humor as an advertising resource.
\end{abstract}

Keywords: humor; advertising evasion; centennials; social networks.

How to cite this article:

González, M. (2020). Diagnosis of risk factors of children in shelters: A strategic proposal for their integral development. Revista Scientific, 5(18), 193-212, e-ISSN: 2542-2987. Recovered from: https://doi.org/10.29394/Scientific.issn.2542-2987.2020.5.18.10.193-212

Date Received: 05-06-2020
Date Acceptance:

27-09-2020
Date Publication:

05-11-2020 


\section{Introducción}

\subsection{Los Centennials y la publicidad digital}

La publicidad digital presenta un constante crecimiento. Las marcas, empresas, incluso los pequeños negocios, invierten cada vez más recursos en la generación de comunicación publicitaria en redes sociales, con el fin de captar la atención de nuevos consumidores. Pero, invertir grandes cantidades de dinero no siempre asegura resultados efectivos.

En la actualidad, persuadir y sobre todo captar la atención del individuo constituye un verdadero reto. Más aún cuando buscamos llegar a una audiencia que ha nacido inmersa en un mundo digital. De acuerdo con Mattelart y Mattelart (2013): "los Estados y las relaciones interestatales ya no son el único ordenamiento del mundo. Las grandes redes de información y comunicación con sus flujos invisibles, inmateriales, forman territorios abstractos que escapan a las viejas territorialidades" (pág. 113); es en este espacio sobresaturado de información y sin barreras de tiempo y espacio donde se desarrollan e interactúan los Centennials.

También conocidos como Generación Z, los Centennials, son aquellos jóvenes que nacieron a inicios del siglo XXI. Tomando el rango propuesto por McGorry y McGorry (2017): son aquellos individuos nacidos específicamente entre 1997 y 2015, un rango que difiere según la posición de cada autor debido a la brecha digital que existe entre países.

Los Centennials fueron denominados por Prensky (2001): como nativos digitales ya que han nacido en un entorno altamente tecnológico; la tecnología se ha convertido, incluso, en extensiones de su cuerpo y mente. Para Arango, Camelo, Huertas, Rodríguez, Sánchez, Sánchez, y Sojo (2019): son “[...] una generación que ha venido tomando un rol crítico y constructivo en las estructuras de consumo, lo que los ha convertido en poderosos decisores de compra" (pág. 8). Esto reafirma la importancia del estudio de este universo y su comportamiento frente a la comunicación publicitaria. 
En la actualidad las palabras publicidad, anuncios, comerciales, propaganda son asociados por muchos como falsedad, mentira, engaño y sobre todo intrusión. En este sentido, Edwards, Li y Lee (2002a): señalan que "la sensación de intrusión ha aumentado y en consecuencia también los sentimientos de irritabilidad que conducen a la evasión publicitaria" (pág. 83). Es ahí, cuando se comienza a cuestionar la verdadera eficacia de las campañas en medios digitales y la necesidad de crear contenidos que no solo capten la atención del individuo, sino también que sean recordadas por éste.

\subsection{La evasión publicitaria y la recordación}

Inicialmente, es necesario comprender la relación entre la evasión publicitaria y la recordación. Para ello nos basaremos en lo señalado por Lindstrom y Kotler (2005a): que presentan seis pasos fundamentales para que una marca sea recordada: exposición, atención, relevancia, penetración, entender los ingredientes de la marca y el arte de vender la percepción. Es decir, un anuncio debe primero ser expuesto a la audiencia y una vez que sea expuesto, debe llamar su atención para aumentar así la probabilidad de ser recordado. No importa la infinidad de veces que un anuncio sea expuesto a una audiencia, si este no logra captar su atención, la probabilidad que sea recordado será baja, ya que el anuncio puede ser evadido por el perceptor.

Es necesario recordar a Speck y Elliot (1997a): quienes definen la evasión publicitaria como "acciones de los usuarios de los medios de comunicación que reducen de manera diferente su exposición al contenido del anuncio. La gente evita los anuncios por medios cognitivos, comportamentales y afectivos" (pág. 61). Una persona tiene diferentes formas de evadir un anuncio publicitario, por lo que a pesar de que un anunciante realice una inversión alta en publicidad a través de redes sociales, esto no asegurará que sus anuncios sean visualizados por la audiencia objetivo.

Según exponen Speck y Elliot (1997b): "una persona puede evadir un 
anuncio ignorándolo (evasión cognitiva), irse de la habitación (evasión afectiva) o cambiar de canal (evasión comportamental)" (pág. 62). Si un anuncio no capta la atención de un individuo, éste podría ser ignorado inconscientemente o conscientemente por el internauta o incluso, llegar a desarrollar una percepción negativa ante el anunciante por interrumpir su navegación. Mencionando a Edwards, Li, y Lee (2002b): manifiestan que "los internautas persiguen objetivos de navegación, cuando los anuncios interrumpen, son percibidos como intrusivos y se desarrollan sentimientos de irritación" (pág. 92). En consecuencia, una campaña podría tener efectos contrarios a los objetivos propuestos por la marca.

En base a esto, surge la necesidad de replantearse la forma de hacer publicidad en redes sociales. Señalando a García (2014): "interrumpir es fácil solo tienes que lanzar el mensaje. Comunicar requiere trabajo, porque necesita humanidad y conexión, algo que solo las personas pueden hacer" (pág. 63). En la búsqueda por lograr aquella conexión entre el anunciante y la audiencia, muchas marcas han optado por apelar a las emociones. En este marco, García (2009), expone que:

Cuando la publicidad apela a deseos y emociones, el receptor sí es susceptible de caer en un papel pasivo, contemplativo; se admira, se fascina ante el mensaje, y de ahí su relación con el imaginario social y las fantasías con las que juega el mensaje publicitario, el cual presenta situaciones agradables, sin conflictos, sin la referencia al fracaso, a la insatisfacción o a la existencia de una realidad frustrante. La publicidad juega con el deseo, aparenta instaurar el reino de la libertad del deseo, aparenta inclinarse más hacia el principio del placer que al de la realidad (págs. 189-190).

El factor emotivo puede tener muchos caminos; una publicidad puede apelar tanto al miedo como a la sorpresa y, tanto a la tristeza como a la diversión. Al presente estamos inmersos en la era de la información, las malas noticias forman parte de la nueva normalidad. Muchas veces se busca en las 
redes, no la conexión con la realidad sino al contrario, una desconexión de esta. Los memes, gifs y stickers divertidos son parte de la comunicación digital. A partir de ello nace la siguiente interrogante: ¿Puede ser el humor un recurso comunicacional que aumente la probabilidad de que un anuncio se recuerde?

\subsection{El humor en la publicidad}

Aunque el estudio del humor es relativamente reciente, varios autores han profundizado su estudio y han llegado a obtener valoraciones positivas del humor como recurso publicitario. Adicionalmente, Fernández (2013), señala que el humor:

Reduce las defensas y los miedos del ponente. La espontaneidad «desenfadada» e hilarante le hace que adopte naturalidad y credibilidad en su exposición. El humor le ayuda a aceptar riesgos y asumir nuevos retos ante cualquier oportunidad que se le presente... (pág. 467).

Por lo tanto, no solo nos acercaría más al perceptor del mensaje, sino que, al reducir la predisposición negativa ante el anuncio, aumentaría la probabilidad de que éste sea visto por el receptor y en consecuencia que sea recuerde. Por ello, no sorprende que este recurso sea utilizado por reconocidas marcas en sus anuncios publicitarios.

El humor, no siempre se consideró un factor influyente. Para este contexto, Salazar (2004a): revela que "la mayoría de anunciantes y creativos publicitarios, quienes temían hacer uso de este estilo publicitario, pues estaban convencidos de que su uso no aportaría ningún beneficio a la publicidad, sino todo lo contario" (pág. 38); con el tiempo esta percepción fue cambiada. Seguidamente, Weinberger, Gulas y Weinberger (2015): expresan que el uso del humor tuvo un aumento dramático desde el año 1925 al 2009, la cifra aumentó de un $21 \%$ a un $66 \%$ para finales del año 2000 . Igualmente, Chung y Zhao (2003): manifestaron que "existen fuertes relaciones positivas entre un 
anuncio humorístico y la actitud hacia el anuncio" (pág. 136). Demostrando la incidencia del humor en percepción de la publicidad en general.

En referencia al tema, Cifuentes y Sánchez (2006): quienes examinaron los efectos del humor en la publicidad colombiana, encontraron que los mensajes con tono humorístico tienen una injerencia positiva en la actitud de compra, pero no necesariamente en la recordación. Un punto con el que difieren autores como Gómez (2002): indicando que "el humor puede captar la atención y grabar el anuncio en la memoria. Los chistes se recuerdan" (pág. 337); esta aseveración es compartida por Palacios-Chavarro, MarroquínCiendúa y López-Giraldo (2020a): quienes realizaron un estudio sobre la incidencia del humor en la recordación de la publicidad televisiva en Colombia, la investigación ratificó al humor como una herramienta importante para la recordación.

Conforme a, Palacios-Chavarro, Marroquín-Ciendúa y López-Giraldo (2020b):

[...] El humor constituye un elemento clave para generar un estímulo hacia la recordación de la marca y del comercial [...] esto muestra también la efectividad y la posibilidad de que los anuncios logren ir más allá de su propósito publicitario y para generar otras significaciones en las audiencias (pág. 13).

Lo que revela la existencia de una relación significativa entre el humor y la memoria. Aunque Palacios-Chavarro, Marroquín-Ciendúa y López-Giraldo (2020c): afirman que el humor tiende a tener un mayor impacto en la recordación de publicidad de productos de menor involucramiento.

Ante los centenares de anuncios a los que se exponen no solo los Centennials sino todo quien navega en redes sociales, encontrar un recurso que contribuya a la atención y consecuentemente a la recordación de un mensaje publicitario se torna un aspecto relevante. En este sentido, y como presenta Salazar (2004b): 
Hoy más que nunca, hacer que se identifiquen y permanezcan en la memoria mensajes y anuncios que establezcan una fuerte conexión entre quien emite (la marca) y quien la recibe (el consumidor) es cada vez más una labor que requiere creatividad (pág. 37).

El objetivo del estudio fue analizar las correlaciones entre la variable independiente (humor) y la variable dependiente (recordación). Examinando a su vez el impacto del humor en la atención y la exposición ante un anuncio publicitario, dos dimensiones establecidas por Lindstrom y Kotler (2005b): como pasos fundamentales para la recordación.

\section{Metodología}

Para el desarrollo de la presente investigación se propuso un estudio correlacional. En conformidad con Hernández, Fernández y Baptista (2010a): "la investigación correlacional asocia variables mediante un patrón predecible para un grupo o población" (pág. 81); este tipo de investigación permite evaluar las relaciones entre dos o más variables.

Se utilizó, un diseño experimental que nos permitiría comprobar o negar las hipótesis correlacionales planteadas. Para Hernández, Fernández y Baptista (2010b): un experimento se define como "situación de control en la cual se manipulan, de manera intencional, una o más variables independientes (causas) para analizar las consecuencias de tal manipulación sobre una o más variables dependientes (efectos)" (pág. 122). Esta manipulación de variables nos permite, además de establecer relaciones entre variables, comprender con mayor profundidad las posibles causas de dichos resultados.

\subsection{Método de recolección de datos}

\subsubsection{Experimento}

En primer lugar, se realizó una prueba piloto donde participaron 8 
individuos entre 18 y 20 años, para evaluar y optimizar los instrumentos de investigación. El preexperimental se realizó vía zoom y se detectaron inconvenientes mínimos, resultado de fallas en la conexión. En la prueba piloto se encontró que existía ya una tendencia hacia la recordación de mensajes con humor.

Para el experimento final se realizaron dos grupos cada uno conformado por 15 personas tomando como referencia la población sugerida como se puede apreciar en la tabla 1.

Tabla 1. Tamaños de muestras mínimas en estudios cuantitativos

\begin{tabular}{|l|l|}
\hline Tipo de estudio & Tamaño mínimo de muestra \\
\hline Transeccional descriptivo & 30 casos por grupo o segmento del universo. \\
\hline Encuesta a gran escala & $\begin{array}{l}100 \text { casos para el grupo o segmento más importante del } \\
\text { universo y de } 20 \text { a } 50 \text { casos para grupos menos } \\
\text { importantes. }\end{array}$ \\
\hline Causal & 15 casos por variables independientes. \\
\hline Experimental & 15 por grupo. \\
\hline
\end{tabular}

Fuente: Hernández, Fernández y Baptista (2010).

Participaron en total 30 sujetos de investigación (15 hombres y 15 mujeres de la ciudad de Quito) entre los 18 y 20 años, bachilleres, y de una clase social y económica media alta. Se controló las características demográficas y geográficas, para garantizar que los hallazgos del estudio no se vean influenciados por una característica en particular.

Para la selección del grupo meta se utilizó el muestreo de bola de nieve. Se seleccionó a individuos que cumplían los requerimientos de la investigación y posteriormente se solicitó a los sujetos de investigación que contactaran a personas que cumplan con las mismas características. Finalmente, se realizó una asignación al azar para formar 2 grupos equivalentes entre sí. El Grupo A visualizó comerciales con la variable independiente humor y el Grupo B comerciales con ausencia de esta variable.

Se envió a cada sujeto de investigación un mensaje con los 
requerimientos para el día del experimento:

- Conectarse desde un dispositivo electrónico con conexión a internet y con audio y cámara activados (De preferencia desde una computadora).

- Se solicitó que cada participante estuviera solo durante el experimento para evitar factores externos de distracción.

- Conectarse 5 minutos antes para verificar la conexión a internet.

Posteriormente se contactó de forma individual vía zoom a cada participante. Se envió un enlace que contenía el video que le correspondía visualizar, dependiendo del grupo al cual pertenecía. De igual forma, debía mantener su audio y cámara encendida durante todo el experimento. La investigadora apagó su audio y cámara, mientras la persona investigada visualizaba los comerciales para evitar distracciones. Una vez finalizada la visualización del video, la investigadora encendió su cámara para aplicar una serie de preguntas que permitieron evaluar la relación entre el humor y la recordación.

\subsubsection{Instrumentos}

1. Dispositivo electrónico con conexión a internet. Audio y cámara activado al conectarse por la plataforma Zoom.

2. Grupo A: 5 spots publicitarios de tono humorístico con una duración de 45 segundos a 1 minuto. Marcas presentadas (Heineken, Sprite, Alto Palermo, Dominus, Netflix).

3. Grupo B: 5 spots publicitarios sin tono humorístico con una duración de 45 segundos a 1 minuto. Marcas presentadas (Heineken, Sprite, Alto Palermo, Dominus, Netflix).

4. Hoja de registro para medir la recordación. 


\section{Resultados}

El estudio reveló que existe una relación entre el tono humorístico del mensaje publicitario y la recordación de una marca. Tal como lo muestra el gráfico 1, los integrantes del Grupo A que visualizaron los anuncios con tono humorístico tendieron a recordar un mayor número de marcas que los integrantes del Grupo B. Mientras que, en el Grupo A, un 53\% logró recordar 4 marcas de los 5 spots visualizados y un $27 \%$ recordó todas las marcas. En el grupo B un $40 \%$ recordó 3 marcas, un $47 \% 4$ marcas y un $0 \%$ las 5 marcas. Gráfico 1. Número de marcas recordadas por los integrantes de Grupo A y Grupo B.

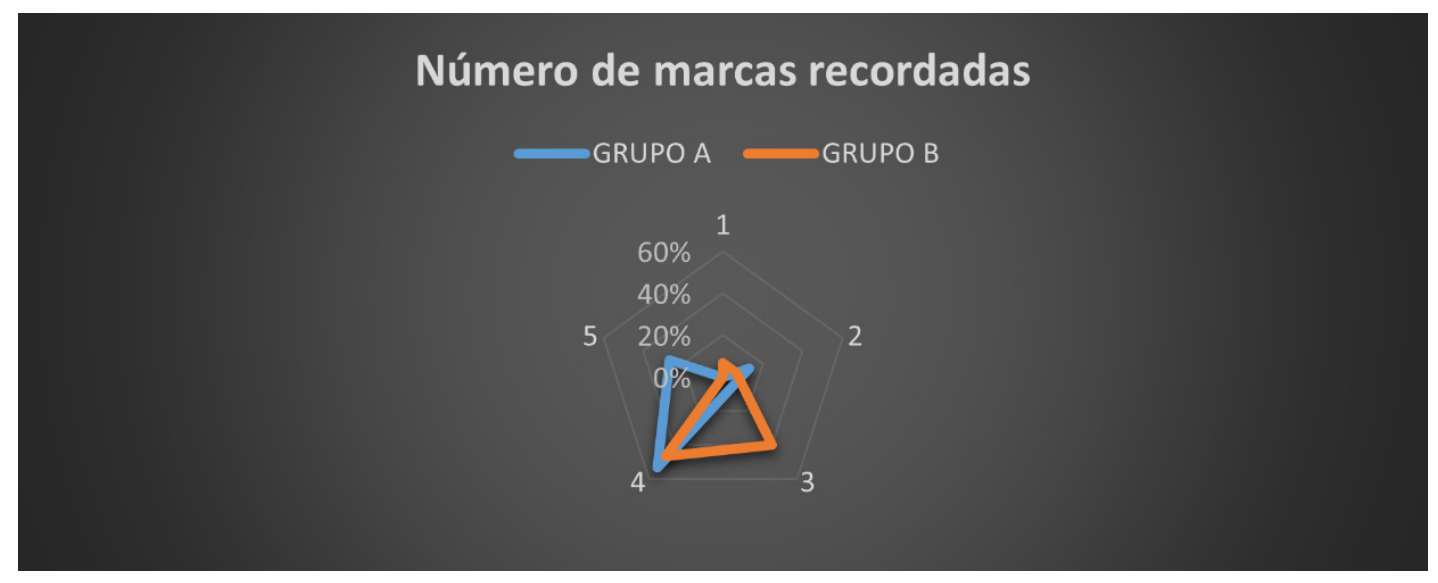

Fuente: Las Autoras (2020).

Adicional a ello, el gráfico 2 demuestra que el humor puede ser un recurso que aporta en la recordación de marcas no posicionadas en la mente del consumidor. A pesar de que Alto Palermo es una marca desconocida por la mayoría de los sujetos de investigación, un $60 \%$ logró enumerar la marca en el Grupo A, mientras que en el Grupo B tan solo un $13 \%$ la recordó.

Asimismo, nos muestra que el humor puede favorecer a su vez a la recordación de marcas ya conocidas por la audiencia objetivo. Netflix es una marca posicionada en el universo de investigación y fue el último comercial 
Instituto Internacional de Investigación y Desarrollo Tecnológico Educativo INDTEC, C.A.

DOI: https://doi.org/10.29394/Scientific.issn.2542-2987.2020.5.18.11.213-233

OAI-PMH: http://www.indteca.com/ojs/index.php/Revista_Scientific/oai

Artículo Original / Original Article

exhibido. A pesar de ello, tan solo un $47 \%$ logró recordar la marca en el Grupo

$B$, mientras que en el Grupo A un 93\% la recordó.

Gráfico 2. Marcas enumeradas por los sujetos de investigación.

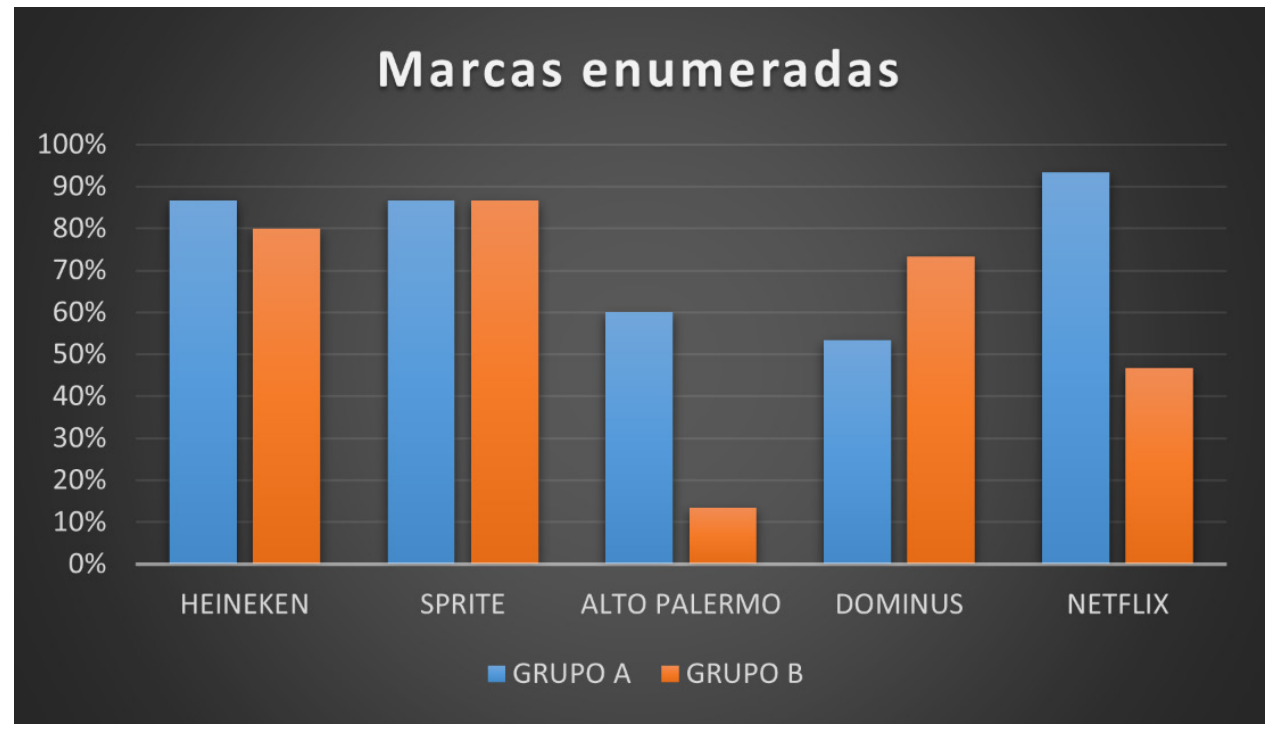

Fuente: Las Autoras (2020).

Gráfico 3. Comprensión del mensaje de los anuncios publicitarios

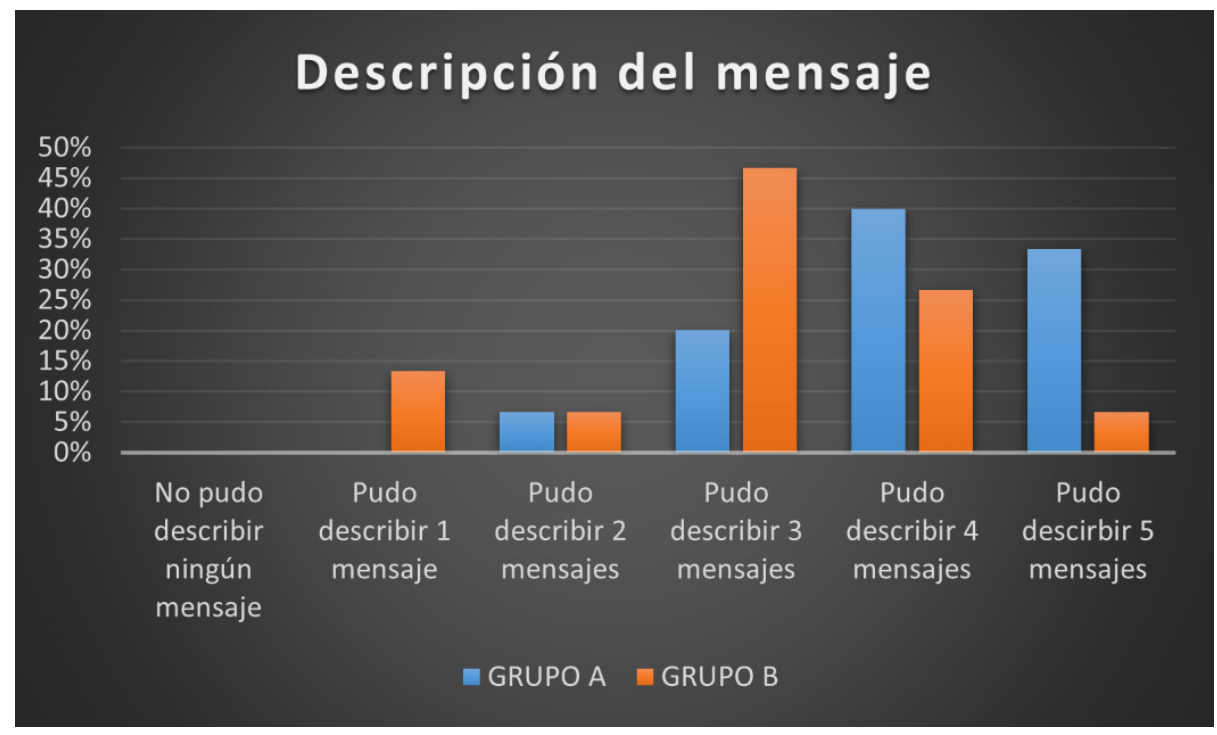

Fuente: Las Autoras (2020). 
El gráfico 3, midió la comprensión del mensaje publicitario de cada anunciante. En el Grupo A un 40\% pudo describir correctamente el mensaje de 4 anuncios visualizados y un 33\% logro describir el mensaje de 5 . En el Grupo B un $47 \%$ logro describir solamente 3 mensajes, un $27 \%$ y un $7 \%$ todos los mensajes. Esto indica que el humor además de beneficiar a la recordación de la marca puede aportar a la recordación y comprensión de aquello que se busca comunicar.

En el grafico 4 se visualiza una relación entre el humor y la atención. Un 87\% de los individuos del Grupo A consideraron al tono humorístico como un factor que influenció en su atención, mientras que los integrantes del Grupo B que visualizaron comerciales con tono emotivo, donde no intervenía el factor humor dieron más importancia al mensaje. Un $60 \%$ lo seleccionó como factor que influencio en su atención.

Gráfico 4. Factores que influyeron en la atención

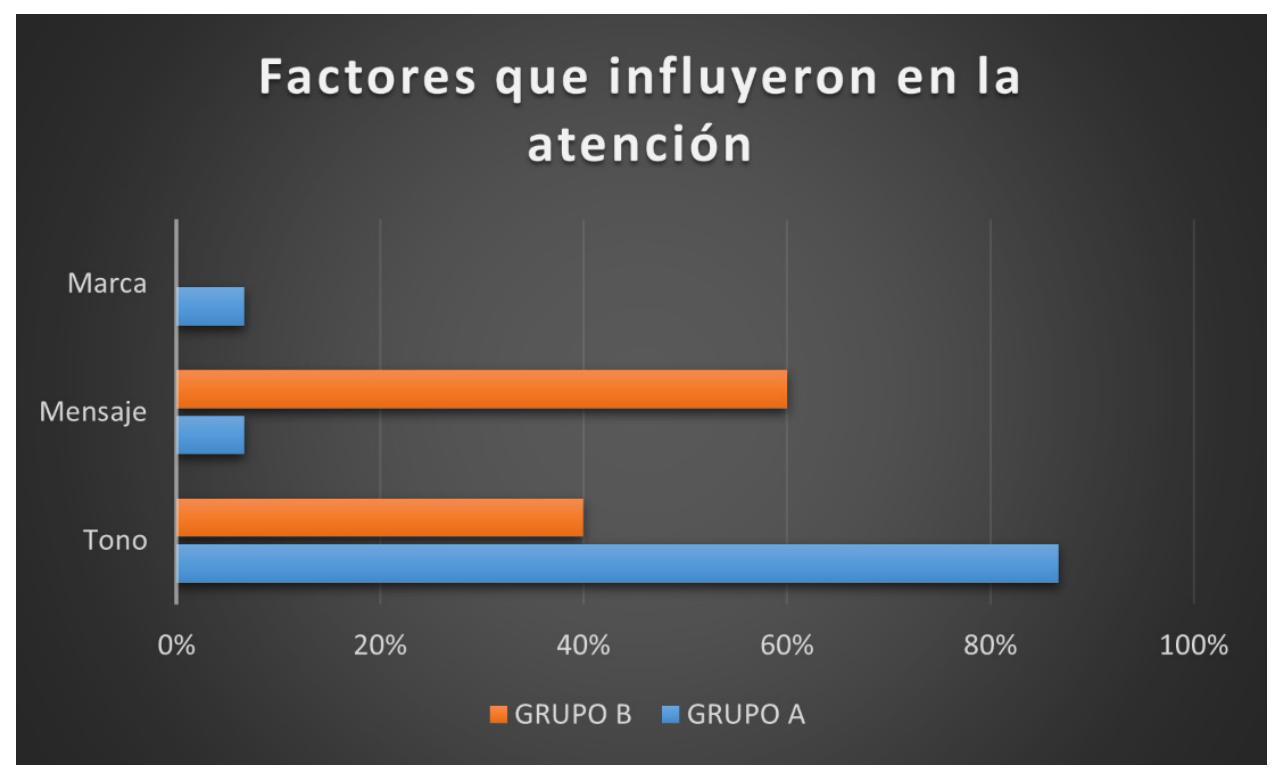

Fuente: Las Autoras (2020).

A juzgar por Lindstrom y Kotler (2005c): la exposición es un factor fundamental para la recordación de un anuncio. Por lo que, para evaluar la 
incidencia del humor en la recordación, se realizó preguntas más específicas a todos los encuestados sobre cada anuncio. De esta manera se determinó el número de veces que tienen que ser visualizados para aumentar la probabilidad de recordación.

El gráfico 5 , revela que el $52 \%$ de los individuos del Grupo B tuvieron que repetirse el anuncio 1 vez y $12 \% 2$ para recordar detalles específicos del spot publicitario. Mientras que los anuncios con tono humorístico fueron recordados con mayor facilidad por el Grupo A. Un $77 \%$ de los entrevistados pudo describir el anuncio la primera vez que visualizó el video, sin la necesidad de verlo nuevamente.

Gráfico 5. Número de veces que se repitió un anuncio para puedan recordar detalles más específicos del anuncio.

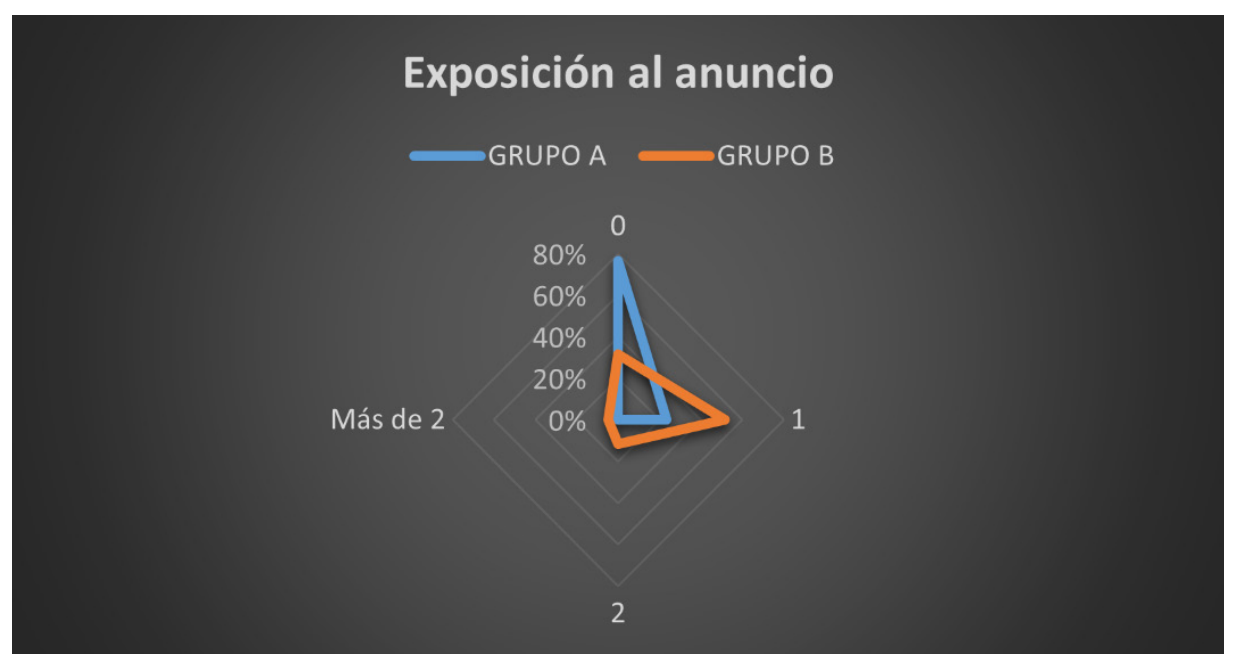

Fuente: Las Autoras (2020).

El gráfico 6, indica que las opiniones frente a la publicidad tienden a ser más positivas cuando se exponen a anuncios con tono humorístico. Un 33\% de los individuos del Grupo A tuvieron una percepción positiva de la publicidad que visualizaban en redes sociales y un $67 \%$ una posición neutral, mientras que en el Grupo B tan solo un 7\% expresó que tenía una posición positiva, un 


\section{Artículo Original / Original Article}

$40 \%$ neutral y un $53 \%$ negativa.

Gráfico 6. Opinión frente a la publicidad que visualizan en redes sociales.

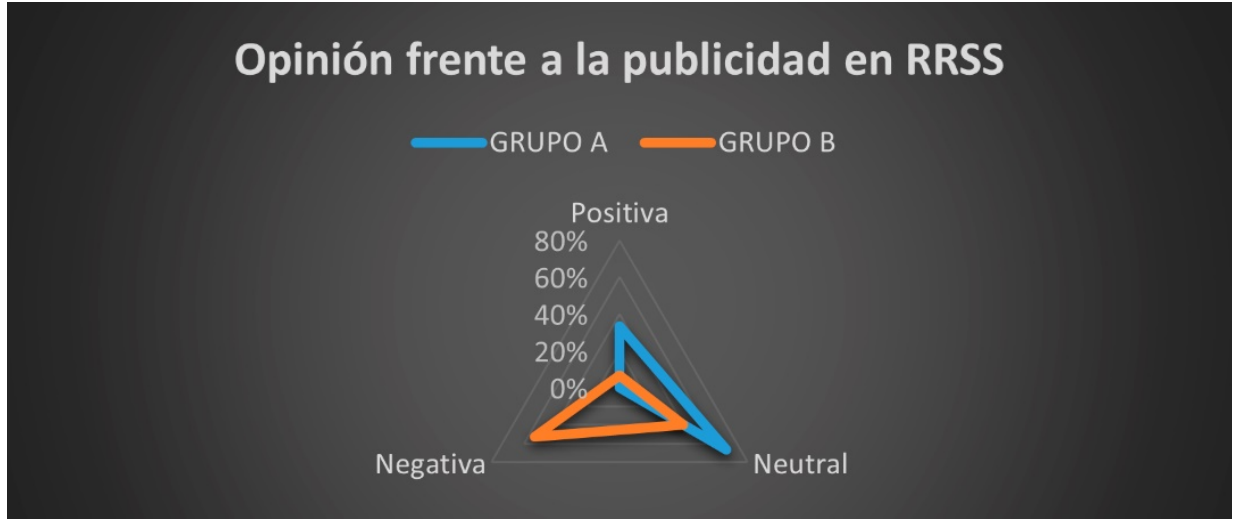

Fuente: Las Autoras (2020).

El gráfico 7 indica que la probabilidad de visualización de un anuncio es mayor cuando interviene el factor humor. Un 53\% del Grupo A manifestó que visualizaría el anuncio, un $33 \%$ tal vez y un $13 \%$ que no lo visualizaría. Por otra parte, en el Grupo B un 47\% expresó que tal vez vería el anuncio, un $40 \%$ que no y un $13 \%$ que sí.

Gráfico 7. Probabilidad de visualización de los anuncios exhibidos en el experimento en redes sociales.

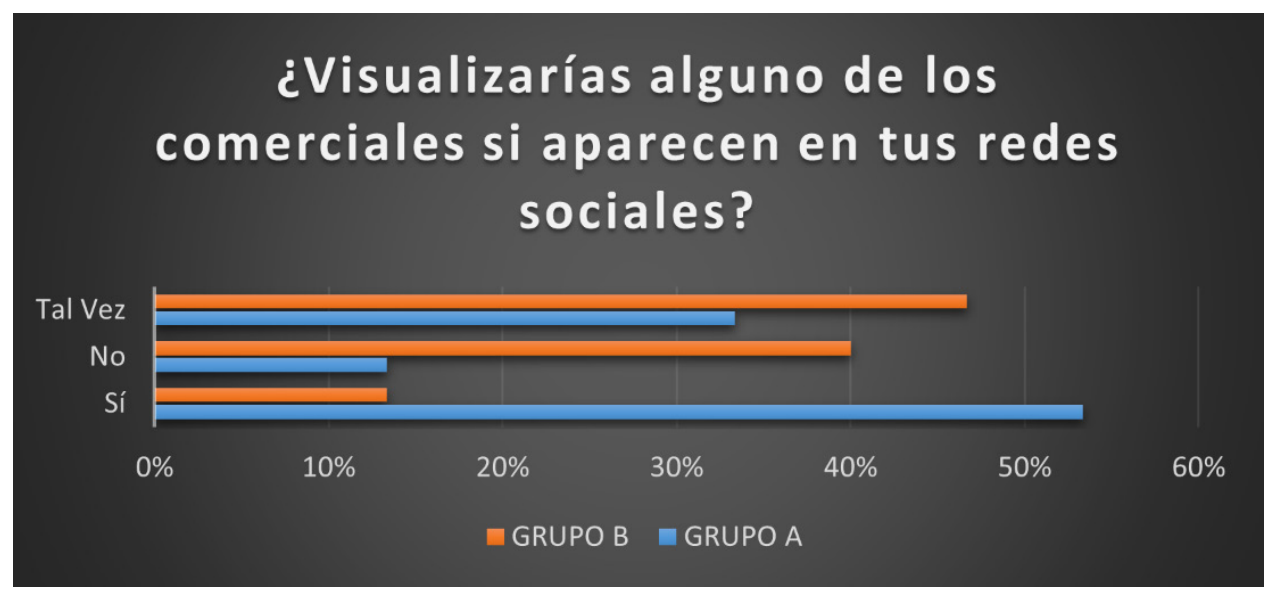

Fuente: Las Autoras (2020). 
Esto revela una relación positiva, no solo entre el humor y la recordación, sino en la predisposición de la audiencia a visualizar los mensajes publicitarios con tono humorístico.

\section{Conclusiones}

La presente investigación demuestra que existe una relación positiva entre la recordación y el tono humorístico de un mensaje publicitario. A pesar de que los Centennials, son una generación exigente debido a la cantidad de información a la que se ven expuestos al navegar en medios digitales, el tono humorístico puede ser un factor que contribuya a la atención y en consecuencia a la recordación de un mensaje.

Ante un centenar de anunciantes y la sobreexposición de "malas" noticias, el humor se presenta como un recurso efectivo para la comunicación publicitaria. Puesto que no solo contribuye a la recordación de marcas no posicionadas en la audiencia objetivo, sino que también impulsa la diferenciación y recordación de marcas ya posicionadas.

Asimismo, se puede concluir que el humor incide tanto en la recordación de una marca, como en la recordación del mensaje publicitario. Lo que permitiría a la marca no solo posicionar su nombre, sino también, sus valores, concepto y esencia de marca en la mente del consumidor.

El humor reduce a su vez la actitud negativa hacia la publicidad en general y consecuentemente, aumenta la probabilidad de visualización del anuncio. Un anuncio que tenga mayor probabilidad de ser visualizado tendrá una mayor probabilidad de ser recordado.

El presente estudio logro cumplir su objetivo de analizar la incidencia del humor en la recordación de mensajes publicitarios exhibidos en redes sociales. Sin embargo, es importante enfatizar que no existe una fórmula mágica para la creación de campañas efectivas. Si bien, el humor es un factor que aumenta la probabilidad de atención y recordación, el formato y la 
duración del anuncio juegan un rol fundamental. Incluso el tipo de humor

puede incidir en la atención y recordación del anuncio. Aspectos que quedan a consideración para futuras investigaciones.

\section{Referencias}

Arango, C., Camelo, C., Huertas, M., Rodríguez, C., Sánchez, C., Sánchez, V., \& Sojo, J. (2019). 1218 Centennials: Generación sin etiquetas. ISBN: 978-958-725-251-4. Bogotá, Colombia: Universidad de Bogotá Jorge Tadeo Lozano.

Chung, H., \& Zhao, X. (2003). Humour effect on memory and attitude: moderating role of product involvement. International Journal of Advertising, 22(1), 117-144, e-ISSN: 0265-0487. Recovered from: https://doi.org/10.1080/02650487.2003.11072842

Cifuentes, C., \& Sánchez, J. (2006). Condicionamiento clásico de tres tipos de humor en publicidad. Universitas Psychologica, 5(1), 101-126, eISSN: 1657-9267. Recuperado de:

https://www.redalyc.org/articulo.oa?id=64750108

Edwards, S., Li, H., \& Lee, J. (2002b). Forced Exposure and Psychological Reactance: Antecedents and Consequences of the Perceived Intrusiveness of Pop-Up Ads. Journal of Advertising, 31(3), 83-95, eISSN. 0091-3367. Recovered from:

https://doi.org/10.1080/00913367.2002.10673678

Fernández, J. (2013). El valor del humor para una comunicación eficaz. Miscelánea Comillas, 71(38), 459-482, e-ISSN: 2341-085X. Recuperado de:

https://revistas.comillas.edu/index.php/miscelaneacomillas/article/view/ $\underline{2265}$

García, I. (2014). Human Media: Las personas en la era de Internet. Barcelona, España: Editorial Zumaque, S.L. 
García, C. (2009). Publicidad y vida cotidiana. La participación de la publicidad en la conformación de la vida cotidiana. Pensar la publicidad, 3(2), 179-196, e-ISSN. 1989-5143. Recuperado de: https://revistas.ucm.es/index.php/PEPU/article/view/PEPU0909220179 $\underline{A}$

Gómez, D. (2002). Publicidad de tono humorístico: Una seria apuesta por el espot divertido. Comunicación: Revista Internacional de Comunicación Audiovisual, Publicidad y Estudios Culturales, 1(1), 333340, ISSN: 1989-600X. España: Universidad de Sevilla.

Hernández, R., Fernández, C., \& Baptista, L. (2010). Metodología de la Investigación. 5ta Edición, ISBN: 978-607-15-0291-9. México: McGraw-Hill / Interamericana Editores, S.A. de C.V.

Lindstrom, M., \& Kotler, P. (2005a,b,c,d). Brand Sense: Build Powerful Brands through Touch, Taste, Smell. ISBN: 978-0749443719. United Kingdom: Gardners Books.

Mattelart, A., \& Mattelart, M. (2013). Historia de las teorías de la comunicación. Barcelona, España: Editorial Paidós.

McGorry, S., \& McGorry, M. (2017). Who are the Centennials: Marketing Implications of Social Media Use and Preferences. DigitalCommons@Kennesaw State University, 179-181, ISSN: 25766805. United States: Kennesaw State University.

Palacios-Chavarro, J., Marroquín-Ciendúa, F., \& López-Giraldo, A. (2020a,b,c). Humor en publicidad televisiva en Colombia: incidencia en la recordación y factores asociados. Revista Espacios, 41(3), 6-25, e-ISSN: 0798-1015. Recuperado de:

https://www.revistaespacios.com/a20v41n03/20410306.html

Prensky, M. (2001). Digital natives, digital inmigrants. From On the Horizon. United Kingdom: MCB University Press.

Salazar, M. (2004a,b). Los aportes del humor en el logro de los objetivos 
Instituto Internacional de Investigación y Desarrollo Tecnológico Educativo INDTEC, C.A.

DOI: https://doi.org/10.29394/Scientific.issn.2542-2987.2020.5.18.11.213-233

OAl-PMH: http://www.indteca.com/ojs/index.php/Revista_Scientific/oai

Artículo Original / Original Article

publicitarios. Revista de comunicación, 33, 36-62, e-ISSN: 2227-1465.

Recuperado de:

https://revistadecomunicacion.com/es/articulos/2004/Art036-62.html

Speck, P., \& Elliott, M. (1997a,b). Predictors of Advertising Avoidance in

Print and Broadcast Media. Journal of Advertising, 26(3), 83-95, eISSN. 0091-3367. Recovered from:

https://doi.org/10.1080/00913367.1997.10673529

Weinberger, M., Gulas, C., \& Weinberger, M. (2015). Looking in through outdoor: a socio-cultural and historical perspective on the evolution of advertising humour. International Journal of Advertising, 34(3), 447-472, e-ISSN: 0265-0487. Recovered from:

https://doi.org/10.1080/02650487.2015.1006082 
OAI-PMH: http://www.indteca.com/ojs/index.php/Revista_Scientific/oai

Artículo Original / Original Article

\section{Melany Cristina Mosquera Álvarez}

e-mail: melacris98@hotmail.com

Nacida en Quito, Ecuador, el 31 de marzo del año 1998.

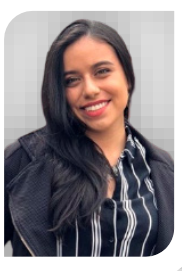

Licenciada en Comunicación Organizacional y Relaciones

Públicas por la Universidad Internacional del Ecuador (UIDE); Poseo experiencia en la creación y ejecución de estrategias de comunicación interna y externa; así como en la producción de piezas gráficas y creación de marca; Dentro de mi trayectoria se encuentra la redacción de reportajes, crónicas y noticias en el diario La Hora; y la participación como asistente de dirección del Departamento de Marketing y admisiones de la Universidad Internacional del Ecuador (UIDE); soy acreedora del premio a segundo lugar en el concurso de periodismo "Gritan Las Aulas" en la categoría de artículo periodístico; La crónica ganadora titulada "Masculinidad Tóxica" se encuentra publicada en el medio digital Wambra. 


\section{Patricia Elizabeth Hidalgo Albuja \\ e-mail: phidalgo@uide.edu.ec}

Nacida en Quito, Ecuador, el 9 de abril del año 1960.

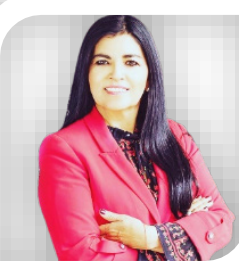

Doctora en Ciencias Sociales por la Facultad Latinoamericana de Ciencias Sociales (FLACSO), Ecuador; Directora de la Escuela de Comunicación de la Universidad Internacional del Ecuador (UIDE); en mi trabajo de investigación y docencia, cuento con 25 años de experiencia, me centro sobre cinco campos específicos que son: la comunicación política, la comunicación organizacional, la planificación estratégica, la democracia participativa y la gestión local; soy autora del libro Claros y Oscuros de la Democracia Participativa: El caso de las asambleas de presupuesto participativo del Distrito Metropolitano de Quito 2010-2013, publicado en el año (2018); Participo como miembro activo de la Asociación Mexicana de Ciencias Políticas (AMECIP), la Asociación Latinoamericana de Ciencia Política (ALACIP), y la Red de Politólogas y del Consejo de Investigación de la Universidad Internacional del Ecuador (UIDE).

El contenido de este manuscrito se difunde bajo una Licencia de Creative Commons ReconocimientoNoComercial-Compartirlgual 4.0 Internacional 